\title{
Attributes of Naturally Fallen (Rained) Melaleuca quinquenervia Seeds in Two Habitat Types of South Florida Wetlands
}

\author{
Min B. Rayamajhi' ${ }^{1}$ Paul D. Pratt ${ }^{2}$, Philip W. Tipping ${ }^{1}$, Jorge G. Leidi' ${ }^{1}$ F. Allen Dray Jr. ${ }^{1}$, \\ Paul T. Madeira1', Ted D. Center ${ }^{1}$ \\ ${ }^{1}$ USDA/ARS, Invasive Plant Research Laboratory, USA \\ ${ }^{2}$ USDA/ARS/WRRC, Exotic and Invasive Weeds Research Unit, Albany, USA \\ Email: Min.Rayamajhi@ars.usda.gov
}

How to cite this paper: Rayamajhi, M.B., Pratt, P.D., Tipping, P.W., Leidi, J.G., Dray Jr., F.A., Madeira, P.T. and Center, T.D. (2017) Attributes of Naturally Fallen (Rained) Melaleuca quinquenervia Seeds in Two Habitat Types of South Florida Wetlands. American Journal of Plant Sciences, 8, 1659-1671.

https://doi.org/10.4236/ajps.2017.87115

Received: May 2, 2017

Accepted: June 20, 2017

Published: June 26, 2017

Copyright $\odot 2017$ by authors and Scientific Research Publishing Inc. This work is licensed under the Creative Commons Attribution International License (CC BY 4.0).

http://creativecommons.org/licenses/by/4.0/ c) $\underset{\mathrm{EY}}{0}$ Open Access

\begin{abstract}
Melaleuca quinquenervia is an Australian tree that has successfully invaded many habitats in Florida. It maintains an aerial seed bank in serotinous capsular fruits held in the tree canopies. These fruits open gradually and shed seeds that fall (rain) throughout the year. Comparative attributes (quantities and qualities) of these fallen seeds from different habitats and tree size categories are unknown. We documented these attributes of fallen $M$. quinquenervia seeds for 12 months among three tree size categories from each of the two hydrologically delineated habitat types. Quantities $\left(8961\right.$ seeds $\left.\mathrm{m}^{2} \cdot \mathrm{mo}^{-1}\right)$ and the viability $(8.8 \%)$ and germinability $(8.4 \%)$ of fallen melaleuca seeds in the occasionally inundated habitat were significantly higher $(P=0.05)$ than the quantities ( 6716 seeds $\mathrm{m}^{2} \cdot \mathrm{mo}^{-1}$ ), and viability $(5.6 \%)$ and germinability $(5.3 \%)$ of melaleuca seeds in the permanently inundated habitat. Although relatively more seeds rained from larger trees, higher quality seeds were rained from the trees of smaller dimensions. Smaller trees typically inhabit at the edges of melaleuca stands and hence they may increase the potential for further spread of seeds into the adjacent areas.
\end{abstract}

\section{Keywords}

Exotic Invasive Tree, Habitat, Seed, Germinability, Viability, Quantity

\section{Introduction}

Melaleuca quinquenervia (Cav.) Blake (melaleuca) is an exotic tree of Australian origin. It has invaded ecologically sensitive wetlands in the Florida Everglades and other surrounding ecosystems that range from pine-palmetto uplands to permanently flooded water conservation areas. Introduced in the late 1880s [1], 
melaleuca has displaced native flora, reduced wildlife habitat, increased fire hazards, and exacerbated human health problems in Florida (e.g., [2] [3]). High reproductive capacity, superior competitive ability due to morphological or physiological plasticity, and rapid growth potential under multiple environmental conditions are often cited characteristics of invasive plants (e.g., [4] [5] [6] [7]) and melaleuca trees in Florida possess many of these invasive traits (e.g., [2] [8] [9] [10]).

High probabilities of seed dispersal, viability and germination enhance melaleuca's ability to colonize diverse habitats [4]. Melaleuca trees can become reproductive as early as one year after germination, and flowering events may repeat several times a year [8]. Inflorescences develop into the infructescence (capsule clusters) composed of 30 to 70 (mean $49 \pm 17$ ) sessile woody capsules each of which contain 200 - 350 seeds (e.g., [8] [11]). These capsules may remain attached to the trunks, branches, or twigs for up to 7 years or sometimes more. Hence the trees are serotinous in nature [8], bearing one to several capsule cohorts (cluster) at any given time [11]. These capsular fruits open when their vascular connections are disrupted by increased bark thickness or other stress factors such as fire, frost, mechanical damage, herbicide treatments, or selfpruning of branches (e.g., [2] [9]).

Seed production by melaleuca trees and their germinability has been noted to be site (habitat) specific [4]. Mature melaleuca tree stands have been reported to produce and retain a large amount of seeds (up to $550 \mathrm{~kg} \cdot \mathrm{ha}^{-1}$ ) in seed capsules held in the canopies for years [12]. A massive synchronous seed release and fall (rain) may occur from these canopy reservoirs following some sudden stresses such as forest fire, seed capsules normally open successively in a non-synchronous manner resulting in a light but constant seed rain (e.g., [2] [9]). In an earlier study, Woodall (1982) [9] reported individual tree based seed rain of 29 seeds $\mathrm{m}^{-2} \cdot \mathrm{d}^{-1}$. These differences in rates of seed rain may indicate inherent variability in the volume of melaleuca seedfall, both in time and space. Under wet conditions, most melaleuca seeds germinate within 10 days, although a small fraction of viable seeds may remain dormant [10]. In a similar study, Van et al. (2005) [13] reported that air dried seeds extracted from healthy mature seed capsules maintained $14 \%-16 \%$ viability and $14 \%$ germinability for 7 -yr when stored at room temperature. Conversely, the same seeds buried at 0.5 to $5 \mathrm{~cm}$ depth retained viability up to 1.5 and 2.3 years in wet and dry sites, respectively [13]. Even though no statistical difference was detected in the overall viability $(8 \%-9 \%)$ and germinability $(6 \%-8 \%)$ of composite seeds extracted from all ages of canopy-held capsulecohorts from occasionally and permanently inundated sites; a trend of low viability and germinability of seeds was observed in permanently inundated sites compared to those from occasionally inundated sites [10]. The overall viability and germinability of seeds retained in canopy held seed capsules peaked among middle age cohorts and decreased towards proximal and distal ends of infructescence bearing stems [10]. Overall, melaleuca's reproductive behavior and environmental plasticity comports well with its invasive nature. 
The aforementioned research confirms melaleuca's massive seed producing ability and its resultant canopy-held seed reservoirs. Any negative impact on the overall quantity and quality of canopy-held melaleuca seeds via chronic damage of foliage, flowers or fruits is expected to suppress the invasive attributes of this exotic tree. Introduced melaleuca biological control agents have been proposed to have such an ability [1] [2]. However, the attribute of naturally fallen (shed in the absence of perturbations) melaleuca seeds in terms of their quantity and quality (viability and germinability) prior to biological control implementation in Florida have not been documented. Documentation of the quantity and quality of naturally falling melaleuca seeds before biological control will be essential for comparing with these attributes observed after implementation of melaleuca biological control program. Herein, we sought to document the quantities of seed fall (rain) while assessing their quality (seed germinability percentages) in two habitat types generally occupied by melaleuca trees of various size-categories encountered in southern Florida. We tested the hypothesis that the habitats and tree-size categories will have no effect on the quantity and quality of melaleuca seeds naturally raining from its canopy reservoirs in southern Florida.

\section{Materials and Methods}

\subsection{Study Sites}

Three habitat types used in this study were delineated based on hydrological attributes of the sites invaded by melaleuca. These occasionally inundated $\left(\mathrm{N} 26.049778^{\circ}\right.$, W80.441556 and $\left.\mathrm{N} 26.052444^{\circ}, \mathrm{W} 80.441278^{\circ}\right)$, and permanently inundated $\left(\mathrm{N} 26.161667^{\circ}, \mathrm{W} 80.356097^{\circ}\right.$ and $\mathrm{N} 26.159667^{\circ}$, W80.365194 ${ }^{\circ}$ ) sites possessing humid subtropical to tropical climate [8] were located in Broward County, Florida (Figure 1). The hydrological attributes of these habitats are based primarily on the descriptions of Brown et al. 1991) [14] and Kushlan 1991) [15]. Habitats designated as "occasionally inundated" may remain inundated (with less than $0.1 \mathrm{~m}$ depth) intermittently for a few hours to several days during or following periods of heavy rain but are neither continuously flooded nor flooded every year, while "permanently inundated" habitats remained inundated year-round [16] where water depth at the research site fluctuated from ca 0.3 - $1.30 \mathrm{~m}$ during June of 1997. Soil types in these habitats are dominated by poorly drained organic muck deposited on limestone beds which are generally classified as Histosols [14]. Melaleuca stands are scattered in and around fresh water marshes often associated with the Florida Everglades and the surface water depths in these habitats fluctuate seasonally [15].

\subsection{Research Plots and Melaleuca Tree Attributes}

Generally, established melaleuca forests form characteristic domes with predominantly larger trees at the center with progressively younger trees, saplings and seedlings near the edges. Two melaleuca domes (hereafter each referred to as a "site") in each habitat were divided into three tree size categories (TSC): "small treesize", at the edge of the dome; "medium treesize", at the mid-section of the 


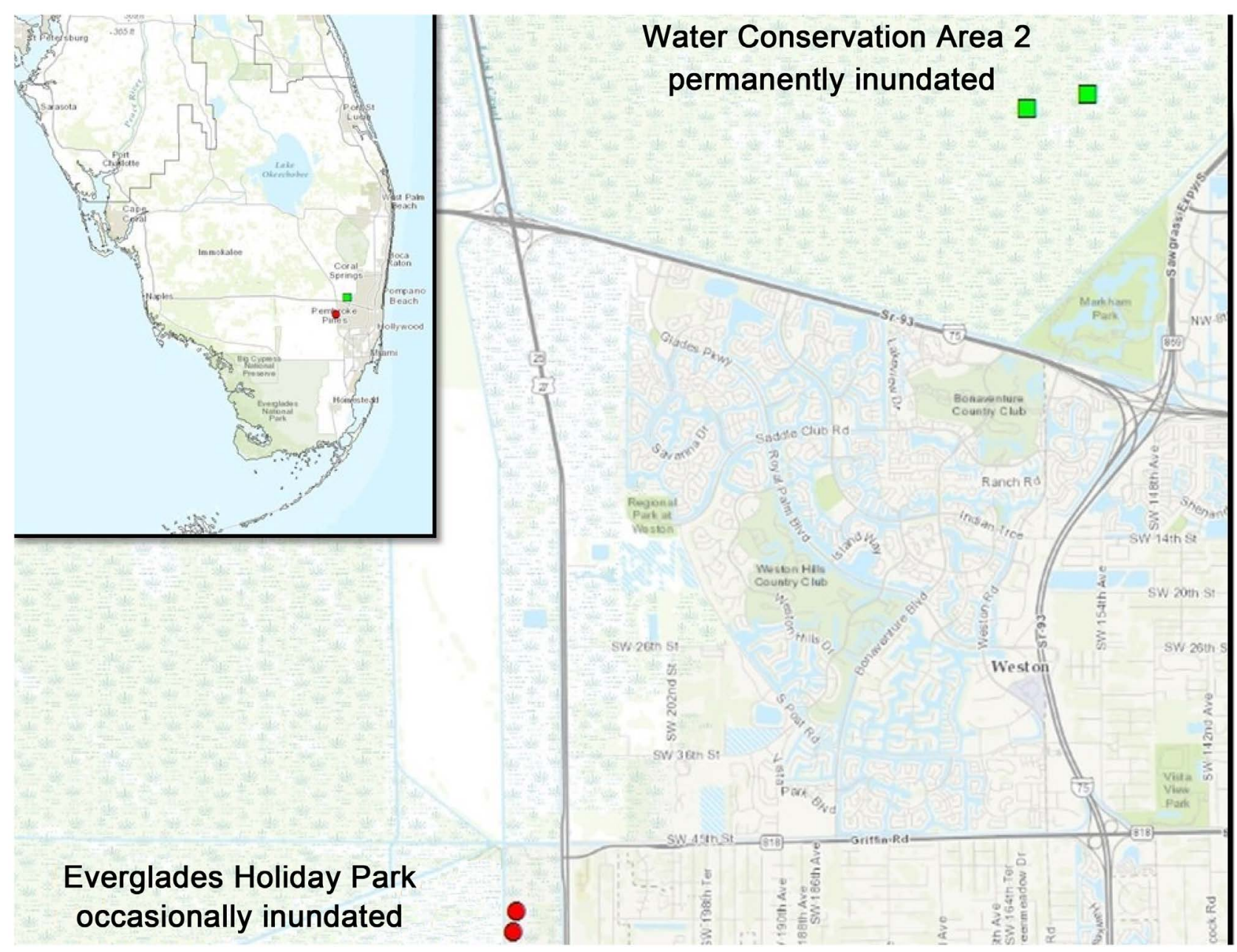

Figure 1. Location of M. quinquenervia infested research habitats in Broward County of South Florida, USA where seed fall studies were carried out. Circular (red) and rectangular (green) dots on the map represent the relative locations of the occasionally and permanently inundated habits, respectively.

dome; and "large treesize", at the center of the dome) based upon the prevalent tree diameter at breast height $(\mathrm{DBH})$ measured at 1.3 meter height from the base. The TSCs were delineated based on their existing position in melaleuca stands. Two permanent plots $(10 \mathrm{~m} \times 10 \mathrm{~m}$ for the large and medium, and $5 \mathrm{~m} \times$ $5 \mathrm{~m}$ for small tree stands) were established in each section of the two sites (each located ca $1 \mathrm{~km}$ apart) within each of the two habitats (Figure 1). These plots' dimensions were determined based on the approximate average heights of the majority of tees in the areas (at the onset of the experiment) where the plots were to be located. A total of 24 ( 3 TSC $\times 2$ plots per TSC $\times 2$ sites $\times 2$ habitats) experimental plots were used in this study.

The DBH of melaleuca trees that were likely to contribute to the seed fall within each habitat and TSC were measured and recorded. These measurements were used to describe the tree attributes (density and DBH; Tables [1] [2]) within each plot in study sites and habitats. Rayachhetry et al. (2001) [17] reported $46 \%-84 \%$ of melaleuca trees to be reproductive as indicated by the presence of the clusters of seed bearing capsules (fruits). 


\subsection{Seed Fall Trapping}

Two wooden framed boxes, each bearing two seed traps, were randomly placed in each plot. Circular seed traps were constructed from 25-cm diameter $(0.098$ $\mathrm{m}^{2}$ ) cylinders that measured ca $15-\mathrm{cm}$ depth and fitted with fine nylon net on one end to catch melaleuca seeds that measured $0.15-0.5 \mathrm{~mm}$ diameter and $0.6-2.0 \mathrm{~mm}$ length. One seed-trap was mounted at each of the two corners of two litter trap plot ${ }^{-1}$ using metallic clips, seed traps were emptied at monthly intervals from July 1997-June 1998. For each habitat type, a total of 48 seed traps were monitored during the study ( 2 sites $\times 3$ tree size categories $\times 2$ plots $\times 2$ boxes $\times 2$ seed traps). Wooden boxes $(0.5 \times 0.5 \mathrm{~m} \times 16$ - $\mathrm{cm}$ deep $)$ were raised with legs to a height ranging from $20-70 \mathrm{~cm}$ above ground level in occasionally inundated sites. Water levels in permanently flooded sites fluctuated from 0.3 to $1.3 \mathrm{~m}$. Therefore, the wooden litter trap boxes were modified to float at least 10 $\mathrm{cm}$ above the water surface by mounting a capped 3.8-liter plastic jar under each of the four corners of the supporting frame and tying them loosely to a nearby tree to secure them in place [16]. This allowed seed traps mounted on two sides of the wooden boxes to float above the water lavel.

\subsection{Seed Quantity}

Melaleuca seeds collected from the two seed traps mounted on each box were bulked during collection to maximize seed number for weighing purposes. Therefore, 24 composite (48 seed traps/2) seed samples were collected habi$\mathrm{tat}^{-1} \cdot \mathrm{month}^{-1}$. Each of these composite seed samples were air-dried at room temperature and the foreign objects, such as bark and twig fragments, leaves, insect frass and other dirt particles, were removed. Seeds were either directly counted (if quantities per trap were small) or weighed and sub-sampled, with overall counts extrapolated from the subsamples and the final tallies have been presented as the number of seeds $\mathrm{ha}^{-1} \cdot \mathrm{mo}^{-1}$.

\subsection{Seed Quality}

Melaleuca seed quality was measured in terms of viability and germinability percentages based either on 200 seeds or the total number of seeds collected, whichever was greater. The germinability test procedures used in this study were the same as described in Rayachhetry et al. (1998). All tests were performed using sterile petri dishes (5-cm diam.), each containing a sterile pad. The pads were soaked with $2 \mathrm{ml}$ of $0.5 \%$ 2,3,5-triphenol tetrazolium chloride (TTC) or sterile deionized water (SDW) that left a thin film of liquid on the surfaces. The seeds were spread onto the soaked sterile pads. The dishes were closed and sealed with Parafilm ${ }^{3}$ and placed in a dark cabinet drawer at room temperature $\left(25^{\circ} \mathrm{C}\right)$. Seed germinability was assessed on 10 and $14 \mathrm{~d}$ after initiation of the testto capture viability and germinability by examining seedmorphology under a dissecting microscope using reflected and/or transmitted light. A seed was considered germinable when an emerging radicle grew out of the seed coat and became visible [10]. 


\subsection{Data Analyses}

In this study, the independent variables were habitat types and melaleuca TSCs and the dependent variables were the quantities (number of seeds per unit area of the melaleuca stands) and qualities (seed viability and germinability) of fallen melaleuca seeds. However, another set of confounding variables within habitats are melaleuca tree densities and DBH that may influence quantity and quality of fallen melaleuca seeds in the study sites within habitats. Therefore, prior to determining the effects of habitat and TSCs on seed it was necessary to determine the effects of habitat on these confounding variables in the habitat. The tree density and DHBs of plots within each habitat were pooled and tested for normality using Shapiro-Wilkin's normality test procedures in Sigma Plot [18]. Overall stem density data passed (W-Statistics $=0.936 ; P=0.117$ ) the normality tests whereas, the DBH data failed (W-Statistics $=0.885 ; P=0.009)$ this test. Therefore, double-sided logarithmic transformed (natural log-transformed) data for plot stem density and DBH were analyzed using GLM procedure [19]. Main effects and interaction terms that were not significant $(P>0.05)$ in the model were dropped and the variables with significant $(P \leq 0.05)$ terms were included in further ad hoc analyses. Multivariate analysis of variance (MANOVA) was applied to assess habitat and TSC effects on confounding variables (density and DBH) as well as the variables of interest (quantity and quality of fallen melaleuca seeds).

The seed viability and germinability percentages were arc-sine transformed [arcsine value $=($ sqrt $($ viability or germinability percentage/100) $)]$ to stabilize the variance prior to further analyses to determine the effects of habitat and TSC on the quantity and quality (viability and germinability) of fallen melaleuca seeds. We examined possible correlations between the mean tree density and corresponding quantity of fallen melaleuca seeds within habitat applying Spearman's Correlation Coefficient test procedure on these transformed data. Mean separation for the effects of habitat were performed using Fisher's protected least significant difference (LSD) while the effects of the TSCs were performed using Duncan's Multiple Range Test procedure. Although analyses were performed using double transformed data in all but stem density as indicated above, actual values related to the number of seeds and their viability and germinability have been used in the figures and tables presented herein.

\section{Results and Discussion}

\subsection{Melaleuca Tree Attributes in Study Habitats}

The main effects of habitat and TSC on tree ( $\geq 1.3 \mathrm{~m}$ tall) density were significant while their interaction habitat ${ }^{*}$ TSC was not significant (Table 1). Tree DBH in the study sites was not affected by habitat and habitats * TSC but it was affected by TSCs (Table 1). Mean density and DBH of the trees in the study sites are presented in Table 2. Statistically, stem densities in occasionally inundated habitats were not different across TSC even though there were relatively fewer stems in large tree size categories. On the other hand, stem densities in small and medium TSC in permanently inundated sites were significantly higher than 
Table 1. Stem density $\left(\# \mathrm{~m}^{2}\right)$ and DBH $(\mathrm{cm})$ of $M$. quinquenervia among tree size-categories (TSC) within two habitat types of South Florida used in seed fall studies.

\begin{tabular}{cccccc}
\hline Source & DF & Type III SS & Mean Square & F Value & $\operatorname{Pr}>$ F \\
\hline Stem Density & & & & & \\
Habitats & 1 & 1.15983945 & 1.15983945 & 8.80 & 0.0078 \\
TSC & 2 & 1.17055204 & 0.58527602 & 4.44 & 0.0262 \\
Habitat ${ }^{\star}$ TSC & 2 & 0.12598204 & 0.06299102 & 0.48 & 0.6274 \\
Stem DBH & & & & & \\
Habitats & 1 & 0.01166625 & 0.01166625 & 0.59 & 0.4519 \\
TSC & 2 & 2.97880017 & 1.489400008 & 75.32 & $<.0001$ \\
Habitat ${ }^{\star}$ TSC & 2 & 0.00398017 & 0.00199008 & 0.10 & 0.9047 \\
\hline
\end{tabular}

Table 2. Tree size-categories (TSC) in the M. quinquenervia seed fall studies in two habitats of South Florida.

\begin{tabular}{ccccc}
\hline \multirow{2}{*}{ Tree size-categories } & \multicolumn{2}{c}{$\mathrm{OI}^{1}$} & \multicolumn{2}{c}{$\mathrm{PI}^{1}$} \\
\cline { 2 - 5 } & Density $\left(\right.$ trees $\left.\mathrm{m}^{2}\right)$ & $\mathrm{DBH}(\mathrm{cm})$ & Density $\left(\right.$ trees $\left.\mathrm{m}^{2}\right)$ & $\mathrm{DBH}(\mathrm{cm})$ \\
\hline Small & $1.6667 \mathrm{a}^{1}$ & $3.7 \mathrm{c}$ & $1.9760 \mathrm{a}$ & $3.8 \mathrm{c}$ \\
Medium & $1.4900 \mathrm{a}$ & $5.4 \mathrm{~b}$ & $2.8350 \mathrm{a}$ & $5.9 \mathrm{~b}$ \\
Large & $0.9450 \mathrm{a}$ & $8.9 \mathrm{a}$ & $1.3900 \mathrm{~b}$ & $9.3 \mathrm{a}$ \\
\hline
\end{tabular}

${ }^{1} \mathrm{OI}=$ occasionally inundated and $\mathrm{PI}^{1}=$ permanently inundated. ${ }^{2}$ Numbers on the column within habitat followed by different letters are significantly different from each other as per Waller-Duncan's multiple range test at $P \leq 0.05$.

those in large TSC (Table 2). Tree stand attributes, such as tree DBH distribution in a forest stand, are important since this parameter is considered as a good predictor of the canopy-held seed reservoir of the serotinous trees (e.g., [17] [20] [21]). This suggests that the production and releases of melaleuca seeds from trees should increase with an increase in tree DBH. Norghauer and Newbery (2015) [22] studied two tree species, Microberliniabisulcata A. Chev and Tetraberliniabifoliolata (Harms) Hauman in rain forests of Africa and reported a nonlinear asymptotic increase in seed production and subsequent releases in two masting events. In this case, the examination of correlations between the mean tree densities showed no significant correlation $(\mathrm{r}=-0.126, P=0.577, \mathrm{~N}=22)$ with the quantity of fallen melaleuca seeds across two habitats. However, viability $(r=-0.363, P=0.0972, \mathrm{n}=22)$ and germinability: $(\mathrm{r}=-0.438, P=0.0412, \mathrm{n}=$ 22) of fallen melaleuca seeds across two habitats indicated a weak to moderately strong correlation with tree densities. This indicated that melaleuca tree density did not effect seed quantity but had some negative effects on their viability and germinability in the studied habitats.

\subsection{Quantities of Fallen Seed by Habitat and TSCs}

The main effect of habitat and its interaction with TSC did not have significant influence on the quantity of fallen seeds, whereas the main effect of TSC did (Table 3). Therefore, corresponding seed quantity data from occasionally and 
Table 3. The overall effects of habitat and tree-size categories (TSC) on the quantity (number of seeds $\mathrm{m}^{2} \cdot \mathrm{mo}^{-1}$ ) and quality (viability and germinability) of fallen M. quinquenervia seeds in South Florida.

\begin{tabular}{cccccc}
\hline Source & DF & Type III SS & Mean square & F Value & Pr $>$ F \\
\hline Quantity & & & & & \\
Habitats & 1 & 8.40339422 & 8.40339422 & 4.68 & 0.0312 \\
TSC & 2 & 15.80776453 & 7.90388226 & 4.40 & 0.0129 \\
Habitat ${ }^{\star}$ TSC & 2 & 6.99597518 & 3.49798759 & 1.95 & 0.1442 \\
Viability & & & & & \\
Habitats & 1 & 0.36865933 & 0.36865933 & 57.23 & $<.0001$ \\
TSC & 2 & 0.08404200 & 0.0420210 & 6.52 & 0.0017 \\
Habitat ${ }^{\star}$ TSC & 2 & 0.05019575 & 0.02509788 & 3.90 & 0.0212 \\
Germinability & & & & & \\
Habitats & 1 & 0.34050272 & 0.34050272 & 48.22 & $<.0001$ \\
TSC & 2 & 0.08211020 & 0.04105510 & 5.81 & 0.0033 \\
Habitat ${ }^{*}$ TSC & 2 & 0.04083512 & 0.02041756 & 2.89 & 0.0568 \\
\hline
\end{tabular}

permanently inundated habitats were pooled and mean separations were performed by TSCs. The mean number of fallen seeds $\left(\mathrm{m}^{2} \cdot \mathrm{mo}^{-1}\right)$ and the average number of seeds per tree are presented by TSC (Table 4$)$.

The overall quantity (number of seeds $\mathrm{ha}^{-1} \cdot \mathrm{mo}^{-1}$ ) of fallen seeds in small and medium TSCs across two habitats were similar but in both these seed quantities were significantly less than the quantities in the large TSCs (Table 4). An average of 8947 seeds fell from a single tree in large TSC compared to 3032 and 4513 seeds in medium and small TSCs, respectively (Table 4). Woodall (1982) [9] studied seed rain pattern in a mature melaleuca tree stand (4600 trees of $>5 \mathrm{~cm}$

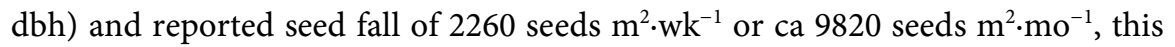
amount approximately matches to the amount we have for our large TSCs. Rayachhetry et al. (2001) [17] conducted a study on melaleuca tree allometry and showed an increase in its canopy-held seed reservoir with the increase in tree sizes. In other systems larger trees in general have also been shown to produce higher number of seeds compared to the trees of smaller sizes (e.g., [23] [24] [25]). These larger trees are expected to generate higher quantities of monthly seed fall in the forest stands. This assumption is corroborated by the results of a study on scots pine (Pinus sylvestris L.) that showed an increase in the number of seeds fallen with an increase in tree sizes [26].

\subsection{Qualities of Fallen Seed by Habitat and TSCs}

The main effects of habitat, TSC, and their interaction terms demonstrated a significant effect on the viability and germinability of fallen melaleuca seeds in our study sites (Table 3 ). Therefore, the seed viability and germinability attributes of fallen melaleuca seeds were analyzed by TSCs within each of the two habitat types. 
Table 4. The effects of tree-size categories (TSC) on the quantity (\# of seeds) and quality (viability and germinability) of $M$. quinquenervia seeds falling from dehisced canopy-held seed-capsules in two habitats of South Florida.

\begin{tabular}{cccc}
\hline Tree size-categories & $\begin{array}{c}\text { Total seed rain } \\
\left(\# \mathrm{~s} \cdot \mathrm{m}^{2} \cdot \mathrm{mo}^{-1}\right)\end{array}$ & $\begin{array}{c}\text { Sample traps } \\
(\mathrm{N})\end{array}$ & $\begin{array}{c}\text { Average seed rain }^{1} \\
\left(\# \mathrm{ste}^{-1} \cdot \mathrm{mo}^{-1}\right)\end{array}$ \\
\hline Small & $8221 \mathrm{~b}^{2}$ & 133 & $4513^{1}$ \\
Medium & $6557 \mathrm{~b}$ & 131 & 3032 \\
Large & $10446 \mathrm{a}$ & 121 & 8947 \\
\hline
\end{tabular}

${ }^{1}$ Average number of seeds tree ${ }^{-1} \cdot \mathrm{mo}^{-1}=$ mean number of fallen seeds $\mathrm{m}^{2} \cdot \mathrm{mo}^{-1}$ /average \# of trees in OI $+\mathrm{PI}$ within corresponding TSCs in Table 2. ${ }^{2}$ Numbers on the column followed by different letters are significantly different from each other as per Waller-Duncan's multiple range test at $P \leq 0.05$.

The viability and germinability of fallen melaleuca seeds among TSCs are shown in Table 5. The viability and germinability of fallen seeds between small and medium TSCs in occasionally inundated habitats were significantly different; however, these two attributes of large TSC were not different from those in small and medium TSCs. These results indicated no clear cut TSC effects on the quality of fallen melaleuca seeds in occasionally inundated habitat. On the other hand, the viability and germinability of fallen melaleuca seeds in permanently inundated habitat decreased with an increase in the TSCs. Overall, the viability and germinability of fallen melaleuca seeds had inverse relationship with the TSCs. Previously, melaleuca seeds held in older seed-capsules cohorts have been reported to have low viability and germinability due to their age; on the other hand, the larger trees tend to have older cohorts (crop) of seed-capsules [17]. Consequently, seeds contributed by the older capsule cohorts may have contributed to the lower seed viability and germinability in larger tree TSCs. A similar decrease in seed germinability with an increased age of the cone crop has also been reported in canopy-held seeds of a serotinous tree Allocasuarina distylla (Vent.) L. Johnson, and $A$. nana (Seib. ex Spreng.) L. [27].

\subsection{Summary of Fallen Seed Quantity and Quality}

When pooled across TSCs, the quantity $(F=5.94, P=0.0153)$, viability $(F=$ 48.55, $P<0.0001)$, and germinability $(F=42.18, P \leq 0.0001)$ of fallen seeds varied significantly between the two habitats. Overall, the occasionally inundated habitat (8961 seeds $\mathrm{m}^{2} \cdot \mathrm{mo}^{-1}$ ) had significantly higher seed fall compared to those in permanently $\left(6716\right.$ seeds $\mathrm{m}^{2} \cdot \mathrm{mo}^{-1}$ ) inundated habitat (Figure $2(\mathrm{a})$ ). Also, the viability of fallen melaleuca seeds in occasionally inundated habitat $(8.84 \%)$ was significantly higher than in permanently inundated habitat (5.47\%); the seed germinability in both habitats ( $8.4 \%$ in occasionally inundated and 5.07 in permanently inundated) followed trends similar to those observed in their respective viability (Figure 2(b)). These data indicate that a small fraction of fallen seeds also appeared to remain dormant in both habitats as described by Rayachhetry et al. (1998) [10] for canopy-held melaleuca seeds.

When averaged across habitats, the quantity $(F=7.04, P=0.0010)$, viability ( $F$ $=3.40, P=0.0346)$, and germinability $(F=4.65, P=0.0102)$ attributes of fallen 


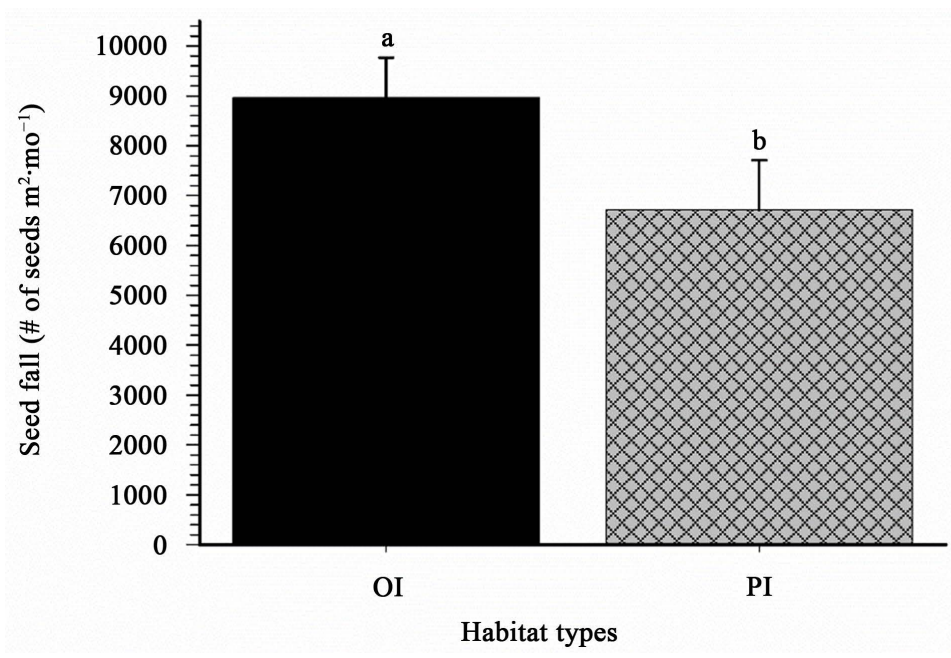

(a)

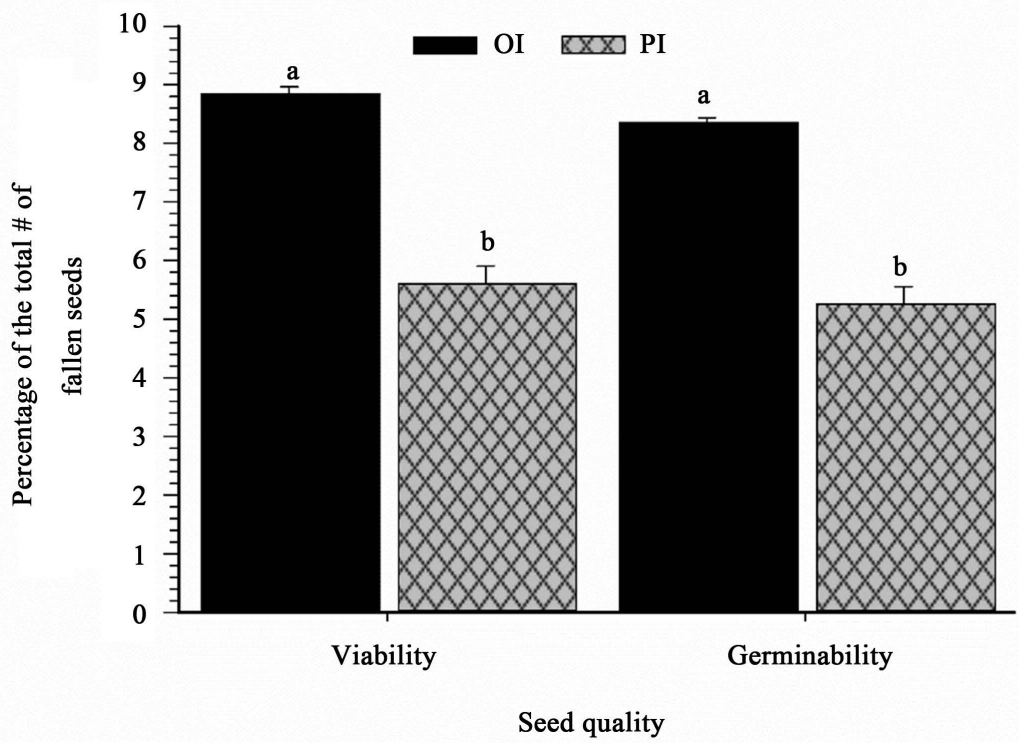

(b)

Figure 2. Summary showing seed quantity (mean number of seeds) and quality (germinability) of $M$. quinquenervia seeds fallen across the three tree size-categories (TSCs) within two hydroperiod based habitat types ( $\mathrm{OI}=$ occasionally-inundated, $\mathrm{PI}=$ permanently inundated)in South Florida; (a) mean seed quantity (number of seeds $\mathrm{m}^{2} \cdot \mathrm{mo}^{-1}, \mathrm{n}=$ 281 in OI); (b) mean seed quality in terms of the percentage of total number of fallen seeds that were viable and germinable in OI $(n=265)$ and PI $(n=96)$. Note, " $n$ " represents the number of seed-traps sampled. Bars with the different letters representing two habitats in a given figure are significantly different at $P=0.05$ according to Fisher's protected least significant difference (LSD) test.

seeds were significantly different among the three TSCs. Large TSCs (10446 seeds $\mathrm{ha}^{-1} \cdot \mathrm{mo}^{-1}$ ) had higher seed fall compared to those in medium (6557 seeds $\mathrm{m}^{2} \cdot \mathrm{mo}^{-1}$ ) and small $\left(8221\right.$ seeds $\mathrm{m}^{2} \cdot \mathrm{mo}^{-1}$ ) TSCs (Table 4$)$. The viability of fallen melaleuca seeds in small TSC (8.92\%) was significantly higher than in medium (7.20\%) and large (7.7\%) TSCs; the seed germinability in two habitats followed trends similar to those observed in viability (Figure 3 ). 


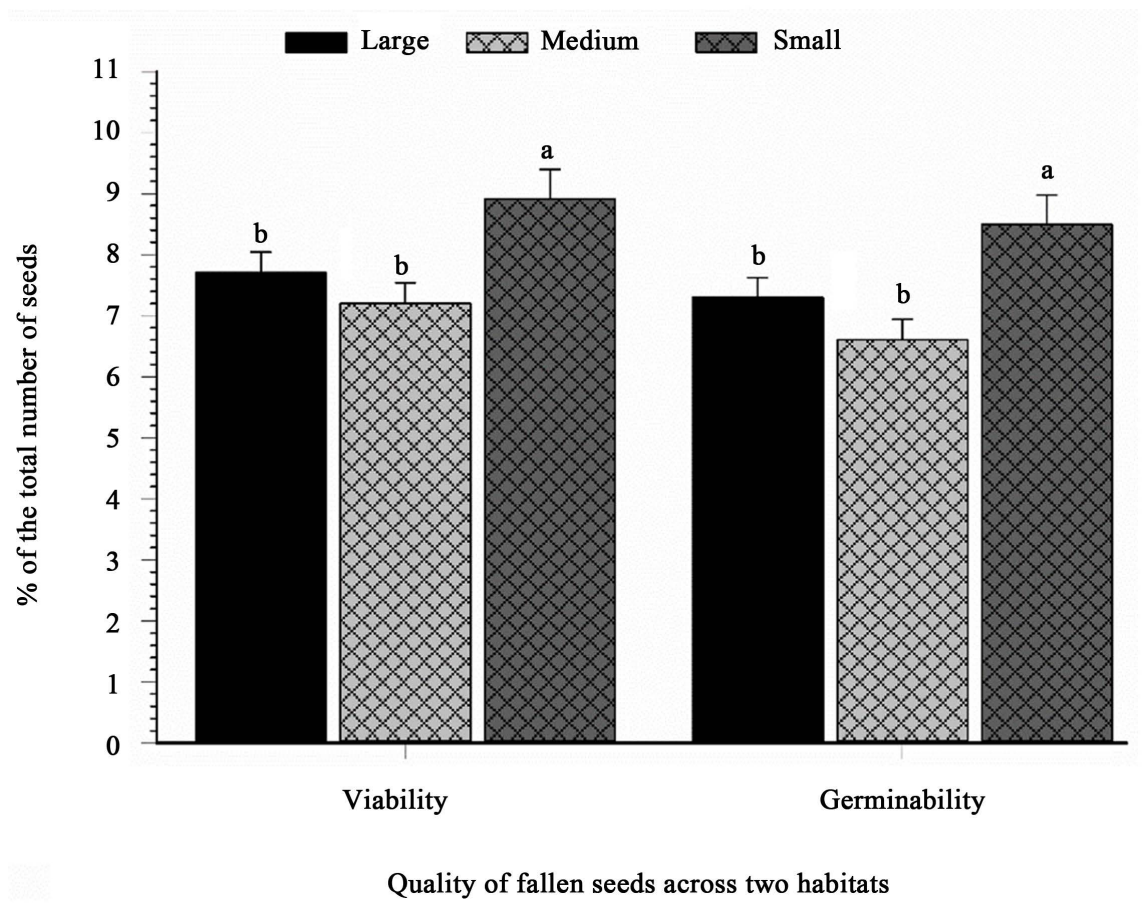

Figure 3. Summary showing the quantity (mean number of seeds) and quality (viability and germinability) of $M$. quinquenervia seeds that fell in three tree size-categories (TSCs) across two (OI and PI) habitats. Mean seed quality expressed in terms of the percentage of total viable and germinable in large $(\mathrm{n}=112)$, medium $(\mathrm{n}=125)$ and small $(\mathrm{n}=124)$ TSCs. Note, "n" represents the number of seed-traps sampled. Bars with the different letters representing seed qualities among three TSCs across two habitats are significantly different at $P=0.05$ according to Waller Duncan's multiple range tests.

Table 5. The effects of tree-size categories (TSCs) on the quality of M. quinquenervia seeds falling from dehisced canopy-held seed-capsules in two habitats of South Florida.

\begin{tabular}{cccc}
\hline Habitats/Tree-sizes & Viability (\% of total) & Germinability (\% of total) & Sample traps (N) \\
\hline OI & & & \\
Small & $9.8 \mathrm{a}$ & $9.3 \mathrm{a}$ & 96 \\
Medium & $8.0 \mathrm{~b}$ & $7.4 \mathrm{~b}$ & 90 \\
Large & $8.7 \mathrm{ab}$ & $8.3 \mathrm{ab}$ & 95 \\
PI & & & 37 \\
Small & $6.8 \mathrm{a}$ & $6.4 \mathrm{a}$ & 41 \\
Medium & $5.3 \mathrm{a}$ & $4.8 \mathrm{ab}$ & 26 \\
Large & $3.5 \mathrm{~b}$ & $3.4 \mathrm{~b}$ & 26 \\
\hline
\end{tabular}

${ }^{1}$ Numbers on the column within habitat followed by different letters are significantly different from each other as per Waller-Duncan's multiple range test at $P \leq 0.05$.

In summary, the quantity and quality of fallen melaleuca seeds was higher in occasionally inundated than in permanently inundated habitats (Table 4 and Table 5) and Figure 2(a) and Figure 2(b)). This trend is consistent with Rayachhetry et al. (1998) [10] who reported less germinability (6.0\%) of canopyheld seeds from permanently inundated sites as compared to $7.8 \%$ from those in 
dry (occasionally-inundated) habitats, since canopy-held melaleuca seed reservoirs contribute to the seed fall in the respective studied habitats. On the other hand, melaleuca stands with predominantly smaller TSCs in both habitats had higher viability and germinability of fallen melaleuca seeds. One explanation for higher quality of seeds among the smaller TSCs may be related to their relative location along the periphery of the stand where their flowers were more accessible to pollinators than those of older trees located within the interior. This hypothesis requires further testing but pollens and pollinators have been reported to play important roles in seed qualities among flowering plants and increased pollinator populations often result in better seed set and greater seed quality in flowering plants [24].

\section{References}

[1] Dray Jr., F.A., Bennett, B.C. and Center, T.D. (2006) Invasion History of Melaleuca quinquenervia (Cav.) S.T. Blake in Florida. Castanea, 71, 210-225.

[2] Hofstetter, R.H. (1991) The Current Status of Melaleuca quinquenervia in South Florida. In: Center, T.D., Doren, R., Hofstetter, R.L., Myers, R.L., and Whiteaker, L.W., Eds., Proceedings of the Symposium on Exotic Pest Plants, US Dept. Interior, Nat. Park Service, Washington DC, 159-176.

[3] Morton, J.F. (1962) Ornamental Plants with Toxic and/or Irritant Properties. II. Proceedings of the Florida State Horticultural Society, 75, 484-491.

[4] Browder, J.A. and Schroeder, P.B. (1981) Melaleuca Seed Dispersal and Perspectives on Control. Proceedings of Melaleuca Symposium, Florida Department of Agriculture and Consumer Services, Division of Forestry, Tallahassee, 23-24 September 1980, 17-21.

[5] Roblin, E. (1994) Alien Invasive Weeds-An Example of National Rivers Authority Sponsored Research. In: De Wall, L.C., Child, L.E., Wade, P.M. and Brock, J.H., Eds., Ecology and Management of Invasive Riverside Plants, John Willey \& Sons, Chichester, UK, 189-193.

[6] Rejmanek, M. and Richardson, D.M. (1996) What Attributes Make Some Plant Species More Invasive? Ecology, 77, 1655-1661. https://doi.org/10.2307/2265768

[7] Goodwin, B.J., McAllister, A.J. and Fahrig, L. (1999) Predicting Invasiveness of Plant Species Based on Biological Information. Conservation Biology, 13, 422-426. https://doi.org/10.1046/j.1523-1739.1999.013002422.x

[8] Meskimen, G.F. (1962) A Silvical Study of the Melaleuca Tree in South Florida. MS Thesis, School of Forest Resources and Conservation, University of Florida, Gainesville.

[9] Woodall, S.L. (1982) Seed Dispersal in Melaleuca quinquenervia. Florida Scientists, 45, 81-93.

[10] Rayachhetry, M.B., Van, T.K. and Center, T.D. (1998) Regeneration Potential of the Canopy-Held Seeds of Melaleuca in South Florida. International Journal of Plant Science, 159, 648-654. https://doi.org/10.1086/297583

[11] Rayamajhi, M.B., Van, T.K., Center, T.D., Goolsby, J., Pratt, P.D. and Racelis, A. (2002) Biological Attributes of the Canopy-Held Melaleuca Seeds in Australia and Florida, US. Journal of Aquatic Plant Management, 40, 87-91.

[12] Rayamajhi, M.B., Pratt, P.D., Center, T.D., Tipping, P.W. and Van, T.K. (2008) Aboveground Biomass of an Invasive Tree Melaleuca (Melaleuca quinquenervia) 
Before and After Herbivory by Adventive and Introduced Natural Enemies: A Temporal Case Study in Florida. Weed Science, 56, 451-456. https://doi.org/10.1614/WS-07-152.1

[13] Van, T.K., Rayamajhi, M.B. and Center, T.D. (2005) Seed Longevity of Melaleuca quinquenervia: A Burial Experiment in South Florida. Journal of Aquatic Plant Management, 43, 39-42.

[14] Brown, R.B., Stone, E.L. and Carlisle, V.W. (1991) Soils. In: Myers, R.L. and Ewel, J.J., Eds., Ecosystems of Florida, University of Central Florida Press, Orlando, Florida, 35-69.

[15] Kushlan, J.A. (1991) Fresh Water Marshes. In: Myers, R.L. and Ewel, J.J., Eds., Ecosystems of Florida, University of Central Florida Press, Orlando, Florida, 324-363.

[16] Rayamajhi, M.B., Van, T.K., Pratt, P.D. and Center, T.D. (2006) Temporal and Structural Effects of Stands on Litter Production in Melaleuca quinquenervia Dominated Wetlands of South Florida. Wetlands Ecology and Management, 14, 303-316. https://doi.org/10.1007/s11273-005-1481-7

[17] Rayachhetry, M.B., Van, T.K., Center, T.D. and Laroche, F.B. (2001) Dry Weight Estimation of the Aboveground Components of Melaleuca quinquenervia Trees in Southern Florida. Forest Ecology and Management, 142, 281-290. https://doi.org/10.1016/S0378-1127(00)00357-1

[18] SigmaPlot (2013) Systat Software, Inc. Version 12.5. San Jose, CA.

[19] SAS Institute (2011) The SAS System for Windows. Version 9.3. SAS Institute Inc., Cary, NC.

[20] Missanjo, E., Ndal0wa, D. and Malinga. D. (2015) Stand Age and Diameter Class Effect on Seed Production of Pinus kesiya Royle ex Gordon Grown in Malawi. Scholars Academic Journal of Biosciences, 3, 173-177.

[21] Viglas, J.N., Brown, C.D. and Johnstone, J.F. (2013) Age and Size Effects on Seed Productivity on Northern Black Spruce. Canadian Journal of Forestry Research, 43, 534-543. https://doi.org/10.1139/cjfr-2013-0022

[22] Norghauer, J.M. and Newbery, D.M. (2015) Tree Size and Fecundity Influence Ballistic Seed Dispersal of Two Dominant Mast-Fruiting Species in a Tropical Rain Forest. Forest Ecology and Management, 338, 100-113. https://doi.org/10.1016/j.foreco.2014.11.005

[23] Brown, J., Enright, N.J. and Miller, B.P. (2003) Seed Production and Germination in Two Rare and Three Common Co-Occurring Acacia Species from Southeast Australia. Austral Ecology, 28, 271-280. https://doi.org/10.1046/j.1442-9993.2003.t01-4-01287.x

[24] Allison, T.D. (1990) Pollen Production and Plant Density Affect Pollination and Seed Production in Taxus canadensis. Ecology, 71, 516-622. https://doi.org/10.2307/1940305

[25] Snook, L.K., Cámara-Cabrales, L. and Kelty, M.J. (2005) Six Years of Fruit Production by Mahogany Trees (Swietenia macrophylla King): Patterns of Variations and Implications for Sustainability. Forest Ecology and Management, 206, 221-235. https://doi.org/10.1016/j.foreco.2004.11.003

[26] Mukassabi, T.A., Polwart, A., Coleshaw, T. and Thomas, P.A. (2012) Scots Pine Seed Dynamics on a Waterlogged Site. Trees, 26, 1305-1315. https://doi.org/10.1007/s00468-012-0706-7

[27] Pannell, J.R. and Myerscough, P.J. (1993) Canopy-Stored Seed Banks of Allocasuarina distylla and A. nana in Relation to Time Since Fire. Australian Journal of Botany, 41, 1-9. https://doi.org/10.1071/BT9930001 
Submit or recommend next manuscript to SCIRP and we will provide best service for you:

Accepting pre-submission inquiries through Email, Facebook, LinkedIn, Twitter, etc. A wide selection of journals (inclusive of 9 subjects, more than 200 journals)

Providing 24-hour high-quality service

User-friendly online submission system

Fair and swift peer-review system

Efficient typesetting and proofreading procedure

Display of the result of downloads and visits, as well as the number of cited articles Maximum dissemination of your research work

Submit your manuscript at: http://papersubmission.scirp.org/

Or contact ajps@scirp.org 